\title{
Emerging Subspecialties in Neurology: Sleep medicine fellowship after child neurology residency
}

Robert C. Stowe, MD, Stacey D. Elkhatib Smidt, MD, and Thornton A. Mason, MD, PhD, MSCE

Neurology ${ }^{\circledR}$ 2020;94:278-281. doi:10.1212/WNL.0000000000008759
Correspondence

Dr. Stowe

stower@email.chop.edu

Pediatric sleep medicine is a multidisciplinary field specializing in the diagnosis and treatment of a wide range of sleep disorders in childhood. Child neurology residency training provides highly desired skills keenly applicable for a prospective sleep medicine fellowship applicant. A fundamental neurophysiology background helps foster an advanced proficiency in the scoring and interpretation of overnight polysomnography and multiple sleep latency tests (MSLTs). Attuned skills in differentiating complex paroxysmal movements are key to distinguishing parasomnias from nocturnal seizures. The clinical evaluation for developmental delay is augmented by learning and applying the normative developmental milestones of sleep in evaluating the sleepy, or sleepless, child. Herein the authors provide an overview of pediatric sleep medicine as it relates to the child neurology trainee seeking subspecialty fellowship opportunities.

\section{A brief introduction to the state of pediatric sleep medicine}

Although there is evidence that humans have theorized about sleep since the time of ancient civilizations, the development of the human EEG in the 1920s jump-started the field of modern sleep medicine. ${ }^{1,2}$ In the 1960 s, the first sleep research society was created and the first sleep center opened at Stanford University. ${ }^{2}$ In 1988, the American Academy of Sleep Medicine (AASM) established the Sleep Medicine Fellowship Training Committee to formalize and streamline training. ${ }^{2}$ Due to physicians coming from various training backgrounds, there were multiple ways to qualify for the American Board of Sleep Medicine (ABSM) examination. ${ }^{2}$ In 2007, the American Board of Internal Medicine (ABIM), American Board of Psychiatry and Neurology, and several other American Board of Medical Specialties member boards began offering an examination in Sleep Medicine as part of a Sleep Medicine Certification Program distinct from the ABSM. ${ }^{3}$ Presently, physicians must complete a 1-year Accreditation Council for Graduate Medical Education (ACGME)-accredited sleep medicine fellowship training program in order to qualify for the examination, which is offered and administered every other year by the ABIM. ${ }^{3,4}$

A 2018 compensation report by the AASM provided a snapshot into the current state of sleep medicine. In this report, $23.2 \%$ of respondents were board-certified in neurology, whereas only $1.9 \%$ were certified in neurology with special qualification in child neurology. ${ }^{5}$ The survey revealed that $\sim 51 \%$ of sleep medicine physicians treat solely adults, $\sim 41 \%$ treat adults and children, and $\sim 9 \%$ treat solely children. ${ }^{5}$ These results demonstrate the opportunity and need for substantial growth in the field of pediatric sleep medicine, particularly from child neurology.

\section{What does a sleep medicine fellowship entail?}

ACGME-approved sleep medicine fellowship programs are 1-year-long multidisciplinary clinical fellowships. Applicants may matriculate from multiple specialties including pediatrics, internal medicine, family medicine, child or adult neurology, pediatric or adult pulmonology, psychiatry,

From the Division of Sleep Medicine (R.C.S., S.D.E.S.), University of Pennsylvania Perelman School of Medicine; and Division of Neurology (R.C.S., S.D.E.S., T.A.M) and Sleep Center (S.D.E.S., T.A.M.), Children's Hospital of Philadelphia, PA.

Go to Neurology.org/N for full disclosures. Funding information and disclosures deemed relevant by the authors, if any, are provided at the end of the article. 
anesthesiology, or otolaryngology. These fellowships have specific adult and pediatric exposure requirements in regards to both patient encounters and the scoring/interpretation of different diagnostic sleep tests detailed by the ACGME. ${ }^{6}$

There are 86 total ACGME-accredited sleep medicine fellowship programs as of March 2019. ${ }^{7,8}$ Three programs are housed within pediatrics departments and 20 programs are housed within neurology departments; the clear majority is within internal medicine and pulmonary/critical care departments. $^{8}$ Through the 2019 National Resident Matching Process (NRMP) match, 180 spots were offered; 54 of 56 (96.4\%) US medical graduates and 147 of 160 (91.9\%) total applicants successfully matched. ${ }^{7}$ Applicants got their first rank choice in $63.1 \%$ of instances, $13.1 \%$ got their second rank choice, $5.6 \%$ matched into their third rank choice, and $10 \%$ matched higher than their third choice. ${ }^{7}$ There are no available public data that discern the different disciplines of ranking applicants to assess their match success.

Through the NRMP in 2019, there were only 8 institutions that designated a specific pediatric track into which an applicant may match $^{7}$; however, numerous other institutions offer enhanced pediatric exposure and concentration to interested and qualified applicants without explicitly providing a rank spot designation through the match.

\section{What is the process of applying to a sleep medicine fellowship?}

Sleep medicine fellowships accept applications through the Association of American Medical Colleges Electronic Residency Application Service (ERAS) on the July cycle. The ERAS application system opens in early June the year prior to the prospective fellowship start date, thus child neurology residents would typically be in their fifth postgraduate year (PGY-5) when applying. The requisite application, personal statement, and at least 3 letters of recommendation would ideally demonstrate high visibility in clinical and academic interest in sleep medicine as a future subspecialty. A sample timeline for child neurology resident application preparation is provided (table 1); interested adult neurology resident applicants would be applying during their PGY-4 years. One advantage to this timeline, compared to some other neurology subspecialties that require applications 18 or more months in advance of prospective fellowship start date, is that it provides residents more opportunity for clinical exposure and research development.

\section{The patients of pediatric sleep neurology}

Choosing a sleep medicine fellowship provides an opportunity to learn a great deal about an essential neurobiological process, its normative features, and the clinical consequences of disruption. Sleep-disordered breathing is one of the most common consultation requests, and the child neurologytrained sleep fellow will become adept at understanding and utilizing treatment options, including positive airway pressure modalities as well as the foundations of mechanical ventilation. A better knowledge of how sleep breathing may influence other health processes such as in children with neuromuscular disorders, epilepsy, and leukodystrophies will help the pediatric neurologist care for the whole patient. Furthermore, the experience of the pediatric neurologist in diagnosing and managing patients with complex genetic and neurodevelopmental disorders will aid the practicing pediatric sleep physician in diagnosing and managing the straightforward to complex sleep disorders of such patients, using behavioral and pharmacologic interventions.

With such a focus on differentiating abnormal paroxysmal events during child neurology residency, sleep medicine fellowship continues to provide opportunities to distinguish sleep-related paroxysmal episodes, from nocturnal seizures to complex parasomnias. The clinical reasoning learned in untangling episodes of altered awareness aids in the evaluation of hypersomnolence, from children with narcolepsy (with or without cataplexy) to Klein-Levin syndrome to insufficient sleep. These patients provide an opportunity to apply a critical understanding of the indications, limitations, and interpretation of MSLTs and maintenance of wakefulness tests. There are continued opportunities to diagnose and treat sleep-related movement disorders, including restless leg syndrome and propriospinal myoclonus.

\section{Research, advocacy, education, future opportunities, and jobs}

Now is an exciting time to be a sleep medicine specialist, especially given the abundant overlap that exists between sleep medicine and neurology research. The complex relationship of circadian rhythms and seizures has exploded into multifaceted clinical research paradigms, such as seizure prediction models, optimization of antiseizure therapeutics based on seizure patterns and influence of sleep on drug delivery to the CNS, and the use of wearable technology in detecting sleep-related seizures. These have essential ties to understanding the complex relationship between and the prevention of ictal apnea and sudden unexpected death in epilepsy. There are exciting investigations in machine-based sleep state analysis from the EEGs of polysomnography to better understand normative sleep parameters across the lifespan and how perturbations may influence outcome and neurodevelopment. At the bench side, there are continued advances in unlocking the intricacies and biological prerogatives of the human circadian clock in various model organisms. Within the realm of complex neurodevelopmental genetic disorders, keen phenotyping of sleep measures and behaviors may help discern molecular underpinnings of sleep disorders and provide avenues for novel therapeutic approaches. 
Table 1 Timeline for applying for Accreditation Council for Graduate Medical Education-accredited sleep medicine fellowships in child neurology residency

\begin{tabular}{ll}
\hline Timing & Procedure \\
\hline PGY-1 through PGY-4 & $\begin{array}{l}\text { Obtain clinical exposure with/without research experience in sleep medicine on elective or selective basis as available } \\
\text { during general pediatric or neurology training }\end{array}$ \\
\hline Late PGY-4 & Ask faculty for at least 3 letters of recommendation; consider obtaining from at least 1 sleep medicine physician \\
\hline Early June of PGY-4 & Applications open via ERAS \\
\hline Early July of PGY-5 & Applications can be sent to fellowship programs \\
\hline Late July to early October of & Interviews \\
\hline PGY-5 & \\
\hline Mid-October of PGY-5 & Rank list deadline via NRMP \\
\hline Late October/early November & Match day \\
\hline
\end{tabular}

Abbreviations: ERAS = Electronic Residency Application Service; NRMP = National Resident Matching Program; PGY = postgraduate year

Numerous opportunities exist for patient advocacy in pediatric sleep medicine. A national and public health debate is underway regarding delaying school start times, especially for adolescents due to inherent high sleep needs and the delayed circadian sleep phase they often develop. This has widespread implications, such as limiting risks of sleepy driving. For student athletes, ongoing research is being conducted regarding how adequate sleep improves performance as well as effective mechanisms to minimize concussions, which can negatively influence sleep.

Recently, there has been a push to incorporate more sleep medicine education into medical school curricula. ${ }^{9}$ A survey of neurology residency programs showed an average of only 5.2 hours devoted to sleep medicine didactics in responding programs while $81 \%$ offered a sleep medicine rotation. ${ }^{10}$ This demonstrates a substantial opportunity for growth regarding exposure to sleep medicine. Several organizations provide additional online resources for trainees (table 2).

The sleep medicine-trained child neurologist seeking employment should consider the desired balance of clinical (between sleep medicine and child neurology) and research activities and the appropriate setting. Academic appointments, particularly in departments/divisions outside of neurology or pediatrics, may incur added nuance due to the complexities of salary sources. Finding the ideal position, as with any career, will require vision, communication, and negotiation.

\section{Future directions/recommendations}

Early exposure to sleep medicine in residency is paramount. In institutions with pediatric sleep medicine faculty, an elective rotation during pediatrics training would provide a background of the breadth of sleep medicine's influences on pediatric care and initiate exposure to neurophysiology concepts prior to commencement of neurology training. Sleep medicine should also be available as an adult neurology clinical elective. Child neurology residencies should consider how to fortify the sleep medicine exposure of their trainees, not only to enhance the training of the general child neurologist, but also to provide trainees with adequate exposure to consider this field as a future career option. In doing so, the child neurology residency programs will allow their trainees to take full advantage of the many opportunities for clinical and research leadership in this young and important discipline.

Table 2 Additional online resources for child neurologists seeking more sleep medicine exposure, information, and education

\begin{tabular}{ll}
\hline Organization/source & Website \\
\hline $\begin{array}{l}\text { American Thoracic Society Pediatric Pulmonary and } \\
\text { Sleep Case Series }\end{array}$ & thoracic.org/members/assemblies/assemblies/peds/ped-case-conference-series/ \\
\hline American Academy of Sleep Medicine & aasm.org/professional-development/choose-sleep/ \\
\hline Sleep Research Society & sleepresearchsociety.org/career-education/ \\
\hline International Pediatric Sleep Association & pedsleep.org/ \\
\hline American Council for Graduate Medical Education & $\begin{array}{l}\text { acgme.org/Portals/0/PFAssets/ProgramRequirements/520_SleepMedicine_2019.pdf? } \\
\text { ver=2019-06-25-122915-670 }\end{array}$
\end{tabular}




\section{Study funding}

No targeted funding reported.

\section{Disclosure}

The authors report no disclosures relevant to the manuscript. Go to Neurology.org/N for full disclosures.

Appendix Authors

\begin{tabular}{llll}
\hline Name & Location & Role & Contribution \\
\hline $\begin{array}{l}\text { Robert C. } \\
\text { Stowe, MD }\end{array}$ & $\begin{array}{l}\text { Children's } \\
\text { Hospital of } \\
\text { Philadelphia }\end{array}$ & Author & $\begin{array}{l}\text { Design and conception of } \\
\text { study and drafted the } \\
\text { manuscript for intellectual } \\
\text { content }\end{array}$ \\
\hline $\begin{array}{l}\text { Stacey D. } \\
\begin{array}{l}\text { Elkhatib } \\
\text { Smidt, MD }\end{array}\end{array}$ & $\begin{array}{l}\text { Children's } \\
\text { Hospital of } \\
\text { Philadelphia }\end{array}$ & Author & $\begin{array}{l}\text { Drafted the manuscript for } \\
\text { intellectual content }\end{array}$ \\
\hline $\begin{array}{l}\text { Thornton A. } \\
\text { Mason, MD, } \\
\text { PhD, MSCE }\end{array}$ & $\begin{array}{l}\text { Children's } \\
\text { Hospital of } \\
\text { Philadelphia }\end{array}$ & Author & $\begin{array}{l}\text { Drafting and revision for } \\
\text { intellectual content }\end{array}$ \\
\hline
\end{tabular}

\section{References}

1. Kirsch DB. There and back again. Chest 2011;139:939-946.

2. Shepard JW, Buysse DJ, Chesson AL, et al. History of the development of sleep medicine in the United States. J Clin Sleep Med 2005;1:61-82.

3. Watson NF, Rosen IM, Chervin RD; Board of Directors of the American Academy of Sleep Medicine. The past is prologue: the future of sleep medicine. J Clin Sleep Med 2017;13:127-135.

4. American Board of Psychiatry and Neurology. 2017 Annual Report. Available at: abpn.com/wp-content/uploads/2018/04/2017_ABPN_Annual_Report.pdf. Accessed April 14, 2019.

5. American Academy of Sleep Medicine. 2018 AASM Physician \& Advanced Practice Provider Compensation Survey. Available at: learn.aasm.org/SecurePdfViewer/web/ viewer.html?file=https\%3a\%2f\%2flearn.aasm.org\%2fPdfPages\%2fSecurePdfHandler.ashx\%3fq\%3d3ordvCHDseeaCxoWd7\%252bZ9\%252brdfcVISJaL5OgaT1UsKJg \%253d. Accessed April 14, 2019.

6. Accreditation Council for Graduate Medical Education. ACGME Program Requirements for Graduate Medical Education in Sleep Medicine (Subspecialty of Child Neurology, Internal Medicine, Neurology, Pediatrics, or Psychiatry). Available at: acgme.org/Portals/0/PFAssets/ProgramRequirements/520_SleepMedicine_2019. pdf?ver=2019-06-25-122915-670. Accessed July 18, 2019.

7. National Resident Matching Program. NRMP Results and Data Specialties Matching Service, 2019 Appointment Year. Available at: mk0nrmpcikgb8jxyd19h.kinstacdn.com/ wp-content/uploads/2019/02/Results-and-Data-SMS-2019.pdf. Accessed April 14, 2019.

8. Accreditation Council for Graduate Medical Education. Sleep medicine (multidisciplinary) programs. apps.acgme.org/ads/public/reports/report/1. Accessed April 14, 2019.

9. Salas RME, Strowd RE, Ali I, et al. Incorporating sleep medicine content into medical school through neuroscience core curricula. Neurology 2018;91:597-610.

10. Avidan AY, Vaughn BV, Silber MH. The current state of sleep medicine education in US neurology residency training programs: where do we go from here? J Clin Sleep Med 2013;9:281-286.

\section{Get NeuroReady!}

Preparing for the neurology boards? Up for recertification? Or just looking for a comprehensive review and update in neurology? Get ready with the AAN's convenient online courses_now with new names! Choose from NeuroReady: Board Prep Edition or NeuroReady: Continuing Certification Edition and get ready to review, self-assess, and succeed. Visit AAN.com/NeuroReady.

\section{Apply for the 2020 Palatucci Advocacy Leadership Program}

The $18^{\text {th }}$ annual Palatucci Advocacy Leadership Forum will take place July 23-26, 2020, at the Hyatt Tamaya Resort in Albuquerque, NM. The Academy desires to help applicants who have a clear passion, strong leadership potential, and an idea on how to advocate on behalf of their patients, community, or profession. The Palatucci Advocacy Leadership Forum will teach you how to:

- Turn your needs and those of your patients into action plans

- Develop media communication skills, whether in front of the camera or through written editorials

- Build and maintain relationships with reporters

- Represent your patients and profession with state and federal representatives

If you see problems or opportunities in your institution, local community, or on a state/national level that you want to address, learn more and apply by the March 9 deadline at AAN.com/view/PALF. 


\section{Neurology}

\section{Emerging Subspecialties in Neurology: Sleep medicine fellowship after child neurology residency}

Robert C. Stowe, Stacey D. Elkhatib Smidt and Thornton A. Mason

Neurology 2020;94;278-281 Published Online before print January 28, 2020

DOI 10.1212/WNL.0000000000008759

This information is current as of January 28,2020

$\begin{array}{ll}\begin{array}{l}\text { Updated Information \& } \\ \text { Services }\end{array} & \begin{array}{l}\text { including high resolution figures, can be found at: } \\ \text { http://n.neurology.org/content/94/6/278.full }\end{array} \\ \text { References } & \text { This article cites } 5 \text { articles, } 1 \text { of which you can access for free at: } \\ & \text { http://n.neurology.org/content/94/6/278.full\#ref-list-1 } \\ \text { Subspecialty Collections } & \text { This article, along with others on similar topics, appears in the } \\ & \text { following collection(s): } \\ & \text { All Education } \\ & \text { http://n.neurology.org/cgi/collection/all_education } \\ & \text { All Pediatric } \\ \text { http://n.neurology.org/cgi/collection/all_pediatric } \\ \text { All Sleep Disorders } \\ \text { http://n.neurology.org/cgi/collection/all_sleep_disorders } \\ \\ \text { Information about reproducing this article in parts (figures,tables) or in } \\ \text { its entirety can be found online at: } \\ \text { http://www.neurology.org/about/about_the_journal\#permissions } \\ \text { Permissions \& Licensing } \\ \text { Information about ordering reprints can be found online: } \\ \text { http://n.neurology.org/subscribers/advertise }\end{array}$

Neurology ${ }^{\circledR}$ is the official journal of the American Academy of Neurology. Published continuously since 1951, it is now a weekly with 48 issues per year. Copyright (C 2020 American Academy of Neurology. All rights reserved. Print ISSN: 0028-3878. Online ISSN: 1526-632X.

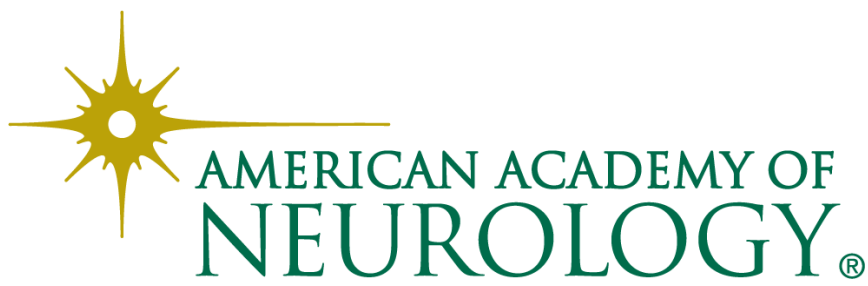

